10-1-2015

\title{
Prognostic role of BNP in children undergoing surgery for congenital heart disease: analysis of prediction models incorporating standard risk factors.
}

\author{
Massimiliano Cantinotti \\ Tuscany Foundation "G. Monasterio" \\ Raffaele Giordano \\ Tuscany Foundation "G. Monasterio" \\ Marco Scalese \\ Institute of Clinical Physiology, Cardiology \\ Sabrina Molinaro \\ Institute of Clinical Physiology, Cardiology \\ Francesca Della Pina \\ Tuscany Foundation "G. Monasterio" \\ Tell us how you used this information in this short survey. \\ Follow this and additional works at: https://digitalcommons.unmc.edu/com_peds_articles \\ Se next page for additional authors \\ Part of the Pediatrics Commons
}

\section{Recommended Citation}

Cantinotti, Massimiliano; Giordano, Raffaele; Scalese, Marco; Molinaro, Sabrina; Della Pina, Francesca; Storti, Simona; Arcieri, Luigi; Murzi, Bruno; Marotta, Marco; Pak, Vitali; Poli, Vincenzo; lervasi, Giorgio; Kutty, Shelby; and Clerico, Aldo, "Prognostic role of BNP in children undergoing surgery for congenital heart disease: analysis of prediction models incorporating standard risk factors." (2015). Journal Articles: Pediatrics. 11.

https://digitalcommons.unmc.edu/com_peds_articles/11

This Article is brought to you for free and open access by the Pediatrics at DigitalCommons@UNMC. It has been accepted for inclusion in Journal Articles: Pediatrics by an authorized administrator of DigitalCommons@UNMC. For more information, please contact digitalcommons@unmc.edu. 


\section{Authors}

Massimiliano Cantinotti, Raffaele Giordano, Marco Scalese, Sabrina Molinaro, Francesca Della Pina,

Simona Storti, Luigi Arcieri, Bruno Murzi, Marco Marotta, Vitali Pak, Vincenzo Poli, Giorgio lervasi, Shelby

Kutty, and Aldo Clerico 
Massimiliano Cantinotti, Raffaele Giordano*, Marco Scalese, Sabrina Molinaro, Francesca della Pina, Simona Storti, Luigi Arcieri, Bruno Murzi, Marco Marotta, Vitali Pak, Vincenzo Poli, Giorgio lervasi, Shelby Kutty and Aldo Clerico

\section{Prognostic role of BNP in children undergoing surgery for congenital heart disease: analysis of prediction models incorporating standard risk factors}

DOI 10.1515/cclm-2014-1084

Received November 4, 2014; accepted March 17, 2015; previously published online April 22, 2015

\begin{abstract}
Background: The routine use of brain natriuretic peptide (BNP) in pediatric cardiac surgery remains controversial. Our aim was to test whether BNP adds information to predict risk in pediatric cardiac surgery.

Methods: In all, 587 children undergoing cardiac surgery (median age 6.3 months; $1.2-35.9$ months) were prospectively enrolled at a single institution. BNP was measured pre-operatively, on every post-operative day in the intensive care unit, and before discharge. The primary outcome was major complications and length ventilator stay $>15$ days. A first risk prediction model was fitted using Cox proportional hazards model with age, body surface area and Aristotle score as continuous predictors. A second model was built adding cardiopulmonary bypass time and arterial lactate at the end of operation to the first model. Then, peak postoperative log-BNP was added to both models. Analysis
\end{abstract}

*Corresponding author: Raffaele Giordano, MD, Tuscany Foundation “G. Monasterio", Pediatric Cardiology and Cardiac Surgery, 54100 Massa, Italy, Phone: +39 0585493622, Fax: +39 0585493616, E-mail: raf_jordan@inwind.it

Massimiliano Cantinotti, Francesca della Pina, Simona Storti, Luigi Arcieri, Bruno Murzi, Marco Marotta, Vitali Pak, Vincenzo Poli and Giorgio lervasi: Tuscany Foundation “G. Monasterio”, Pediatric Cardiology and Cardiac Surgery, Massa, Pisa, Italy

Marco Scalese and Sabrina Molinaro: Institute of Clinical

Physiology, Cardiology, Pisa, Italy

Shelby Kutty: University of Nebraska Medical Center, Omaha, NE, USA

Aldo Clerico: Tuscany Foundation "G. Monasterio", Biochemical Laboratory, Massa, Pisa, Italy; and Scuola Superiore Sant'Anna, Pisa, Italy to test discrimination, calibration, and reclassification were performed.

Results: BNP increased after surgery $(\mathrm{p}<0.001)$, peaking at a mean of $63.7 \mathrm{~h}$ (median $36 \mathrm{~h}$, interquartile range 12-84 h) post-operatively and decreased thereafter. The hazard ratios (HR) for peak-BNP were highly significant (first model $H R=1.40, p=0.006$, second model $H R=1.44$, $\mathrm{p}=0.008$ ), and the log-likelihood improved with the addition of BNP at $12 \mathrm{~h}(\mathrm{p}=0.006 ; \mathrm{p}=0.009)$. The adjunction of peak-BNP significantly improved the area under the ROC curve (first model $\mathrm{p}<0.001$; second model $\mathrm{p}<0.001$ ). The adjunction of peak-BNP also resulted in a net gain in reclassification proportion (first model NRI $=0.089$, $\mathrm{p}<0.001$; second model NRI $=0.139, \mathrm{p}=0.003$ ).

Conclusions: Our data indicates that BNP may improve the risk prediction in pediatric cardiac surgery, supporting its routine use in this setting.

Keywords: brain natriuretic peptide (BNP); congenital heart disease; pediatric cardiac surgery.

\section{Introduction}

B-type natriuretic peptides are considered the first-line biomarkers for adult patients with acute or chronic heart failure according to the most recent international guidelines [1]. The interest in brain natriuretic peptide (BNP) has also progressively increased for pediatric patients undergoing cardiac surgery [2-17]. Several studies have indicated that in children undergoing surgery for congenital heart disease (CHD), BNP levels (especially those measured preoperatively) are independently associated with markers of outcome including the duration of mechanical ventilation, intensive care unit (ICU) stay, need for inotropic support, and low cardiac output syndrome [1-17]. However, the clinical efficacy and benefits of BNP use in children remains 
controversial owing to the limited number of studies with high statistical power [17]. As a result, although several studies have suggested the use of BNP, currently no definitive indications or recommendations exist regarding its routine use as a diagnostic and prognostic marker in children with CHD undergoing cardiac surgery [1-17].

According to the latest guidelines [18-20], the evaluation of the diagnostic and/or prognostic accuracy of a biomarker is only an early step to prove its clinical efficiency and effectiveness. Criteria for assessing the clinical relevance and cost effectiveness of cardiovascular risk biomarkers have recently been revised [18-20]. These criteria indicate a multi-step analysis, requiring a specific statistical approach [18-20], which has never been adopted in studies evaluating the use of biomarkers in pediatric cardiac surgery. Accordingly, a statistically significant association between a specific biomarker and the outcome, even in a multivariable model, is not sufficient to prove its predictive value [18-20]. Indeed, it is necessary to demonstrate that the novel biomarker provides additional prognostic information, beyond that provided by established cardiac risk factors. This evidence is usually provided by means of discrimination, calibration, and reclassification tests in a sound research design [18-20]. Therefore, the aim of this work is to evaluate whether the use of BNP may add information to risk prediction of children undergoing surgery for CHD, beyond that provided by established cardiac risk factors.

\section{Materials and methods}

\section{Study protocol}

All children undergoing corrective or palliative CHD surgery between July 2009 and December 2013 at the Department of Pediatric Cardiac Surgery were prospectively enrolled. Children previously palliated (including shunts, pulmonary artery banding, Norwood stage 1 procedure, cavo-pulmonary palliation) were included, while patients undergoing redo surgery were excluded.

Pre-operative demographic and clinical parameters including age, gender, weight, height, and body surface area (BSA), and biochemical characteristics were recorded. In addition, cardiopulmonary bypass (CPB) time for each patient was documented. Informed written consent was obtained from the parents of all patients enrolled in the study. The Institutional Review Board and Ethics Committee approved the study protocol.

\section{Blood samples}

Samples of plasma for the BNP assay were collected pre- and postoperatively (at 12, 36, 60, 84, $108 \mathrm{~h}$ after surgery and thereafter every day during the ICU stay, and up until discharge). In order to reduce the blood volume per patient, BNP values were measured using the residuals of specimens needed for the standard clinical practice, and so no additional samples were collected. Plasma BNP levels were measured using the fully automated Access platform (Triage BNP reagents, Access Immunoassay Systems, REF 98200, Beckman Coulter, Inc., Fullerton, CA, USA). The characteristics and performance of the Access Immunoassay method were previously evaluated in our laboratory [21]. Arterial blood gases and arterial lactate were measured for each sample using a fully automated assay (ABL 700 series Radiometer, Copenhagen, Denmark) at the time of conclusion of surgery.

\section{Surgical and medical management}

The pre-operative anesthesia approach, intra-operative CPB strategy, and post-operative ICU management followed standard institutional practice as described in previously published studies [10, 14-17]. Non-iodinated topical antiseptics were used for every patient. A standard technique was used to institute CPB (roller pump, disposable membrane oxygenator and arterial filter) and involved bicaval drainage and ascending aorta perfusion. Different myocardial protection approaches (anterograde cold crystalloid or blood cardioplegia) and degrees of body cooling were used (ranging from $19^{\circ} \mathrm{C}$ to $35^{\circ} \mathrm{C}$ ), depending on the surgical strategy. In the post-operative period, hemodynamic management consisted of epinephrine (0.005-0.15 $\mu \mathrm{g} / \mathrm{kg} / \mathrm{min})$, milrinone $(0.5-0.75 \mu \mathrm{g} / \mathrm{kg} / \mathrm{min})$, dopamine $(5-20 \mu \mathrm{g} / \mathrm{kg} /$ $\mathrm{min})$, and noradrenaline $(0.05-0.5 \mu \mathrm{g} / \mathrm{kg} / \mathrm{min})$. Intravascular volume expansion was utilized as needed and consisted of $20 \%$ human albumin or fresh frozen plasma. Diuretic management usually involved furosemide (1-10 mg/kg/day). Echocardiographic evaluation was performed at every hormonal blood sample interval according to current guidelines [22].

\section{Outcome and variables definitions}

According to the current recommendations [23], major complication is defined as 1) operative mortality; or 2) any one or more of the following occurring within 30 post-operative days including: a) renal failure, b) neurological deficit, c) arrhythmia necessitating pacemaker, d) extra-corporeal membrane oxygenation/ventricular assist device, e) paralyzed diaphragm, f) unplanned operation.

The surgical procedures were classified according to the Aristotle risk adjustment score, which evaluates and ranks the complexity of 145 corrective and palliative surgical procedures for CHD [24-26]. Primary outcomes were major complications and ventilator days over 15 days. Extubated patients (i.e., without major complications) within 15 days after surgery were censored.

\section{Statistical analysis}

Continuous variables are summarized as median and interquartile range, and categorical variables as counts and percentages. Non-normally distributed variables were log-transformed when appropriate. Comparison between groups was performed using Mann-Whitney U-test or $\chi^{2}$-test. 
BNP values over time were evaluated using Friedman test followed by Wilcoxon test with Bonferroni correction for post-hoc comparisons. Spearman's rho correlation test was used to analyze the statistical association between pre- and post-surgery values and markers of outcome [27].

The prognostic value of BNP (using log-transformed values) was assessed by investigating the capacity to ameliorate the prediction of outcome in two sets of Cox proportional hazards analyses: 1) A prediction model with traditional risk factors $[23,24]$ including age, Aristotle score and BSA as continuous predictors; 2) a second risk prediction model was built, adding to the first model two operative parameters, $\mathrm{CPB}$ time and arterial lactate values at the end of operative time, commonly used for the risk stratification in pediatric cardiac surgery $[28,29]$. To test the prognostic value of BNP, pre- and post-operative BNP values were added to both models. The proportional hazards assumptions of all Cox proportional hazards analyses were assessed with Schoenfeld's tests, if relevant violations were observed we used flexible parametric survival models developed by Royston and Parmar [30]. In order to test the discriminative ability of BNP, the area under the curve by receiver operating characteristics (ROC) analysis was evaluated and compared using the DeLong method [31]. The net reclassification improvement (NRI) [32] was used to assess the proportion of individuals reclassified correctly by the addition of BNP, and the likelihood ratio (LR) test was used to assess improvement in model fit from addition of BNP (model fit). The Harrell C statistic (only for Cox model) was used to assess the proportion of concordance between predicted and observed events in order to evaluate the calibration. Internal validation of the model was made with the cross-validation method with two groups of omitted observations using regression modelling strategies by Frank E. Harrell Jr [33]. The NRI was calculated based on reclassification across tertiles of risk categories yielded by new models in comparison with the reference model. A p-value $<0.05$ was considered statistically significant. Statistical analyses were performed using Stata 10 (StataCorp, College Station, TX, USA) and R 3.1.2 software.

\section{Results}

\section{Study patients}

The study population included 587 children (318 males and 269 females), who underwent CHD surgery. The median age was 6.3 months (1.2-35.9). Pre-operative demographic, clinical, biochemical parameters and post-surgery details for all study patients are listed in Table 1.

\section{BNP post-surgical levels}

BNP values increased progressively after surgery peaking at a mean of $63.65 \mathrm{~h}$ (median $36 \mathrm{~h}$, inter-quartile range $12-84 \mathrm{~h}$ ) post-operatively $(\mathrm{p}<0.001)$ and then progressively decreased. However, at discharge (median $228 \mathrm{~h}$, interquartile range 132-396 h post-surgery) BNP values were still significantly different from baseline $(p<0.001)$ (Figure 1).
Table 1: Patients characteristics.

Total $(n=587)$

\begin{tabular}{|c|c|}
\hline \multicolumn{2}{|l|}{ (A) Baseline characteristics } \\
\hline Age, median, IQ & 6.3 months $(1.2-35.9)$ \\
\hline Gender, male & $318(54.3)$ \\
\hline Weight, kg & $6.0(3.6-13.0)$ \\
\hline Height, cm & $64(52-90)$ \\
\hline BSA Haycock, m² & $0.33(0.23-0.59)$ \\
\hline Cavo-pulmonary connection & $35(6.0)$ \\
\hline Biventricular volume overload & $6(1.0)$ \\
\hline LV pressure overload & 69 (11.8) \\
\hline LV volume overload & $172(29.4)$ \\
\hline Palliated univentricular heart & $15(2.6)$ \\
\hline RV pressure overload & $114(19.5)$ \\
\hline RV volume overload & $66(11.3)$ \\
\hline Transposition of the great arteries & $53(9.0)$ \\
\hline Univentricular heart & $56(9.6)$ \\
\hline BNP, ng/L & $93(35-558)$ \\
\hline \multicolumn{2}{|l|}{ Aristotele $A B C$ classification } \\
\hline Category I: $1.5-5.9$ & 65 (11.1) \\
\hline Category II: 6-7.9 & $223(38.1)$ \\
\hline Category III: 8-9.9 & $195(33.3)$ \\
\hline Category IV: $10-15$ & $102(17.4)$ \\
\hline \multicolumn{2}{|l|}{ (B) Post-surgery details } \\
\hline BNP $12 \mathrm{~h}$ & $429(242-908)$ \\
\hline BNP peak & $694(305-1522)$ \\
\hline Lactate $2 \mathrm{~h}$ & $1.7(1.1-3.0)$ \\
\hline CPB time, $\min$ & $106(65-141.5)$ \\
\hline Cross-clamp, min & $54.5(23-81)$ \\
\hline TTE, h & $15(8-75)$ \\
\hline Hours in ICU & $36(24-132)$ \\
\hline Inotropic time, $\mathrm{h}$ & $36(12-106)$ \\
\hline Major complications & $64(10.9)$ \\
\hline
\end{tabular}

BNP, brain natriuretic peptide; BSA, body surface area; $\mathrm{H}$, hours; $I C U$, intensive care unit; IQ, interquartile range; LV, left ventricle; RV, right ventricle; TE, time to extubation. CHD groups: Glenn, univentricular heart after partical pulmonary cavo-connection; LVVO, left ventricle volume overload (patenent arterial duct, ventricular septal defects, etc); LVPO, left ventricle pressure overload (aortic stenosis, aortic coarctation, etc); RVPO, right ventricle pressure overload (tetralogy of Fallot, pulmonary stenosis); RVVO, right ventricle volume overload (atrial septal defect, anmalous pulmonary venous drainage, etc); TGA, transposition of the great arteries; UH, univentricular heart; Palliated UH, univentricular heart after first stage of Norwood palliation.

\section{BNP values versus clinical outcomes}

Both pre- and post-operative BNP values were significantly correlated with BSA, Aristotle score, and with outcome parameters, including duration of intubation, inotropic administration, and length of stay in the ICU (Table 2). Furthermore, a significant association between BNP values before and after surgery was found $(\rho=0.69$, $\mathrm{p}<0.001)$. Post-surgery BNP also significantly correlated with ejection fraction $(p<0.05)$. 


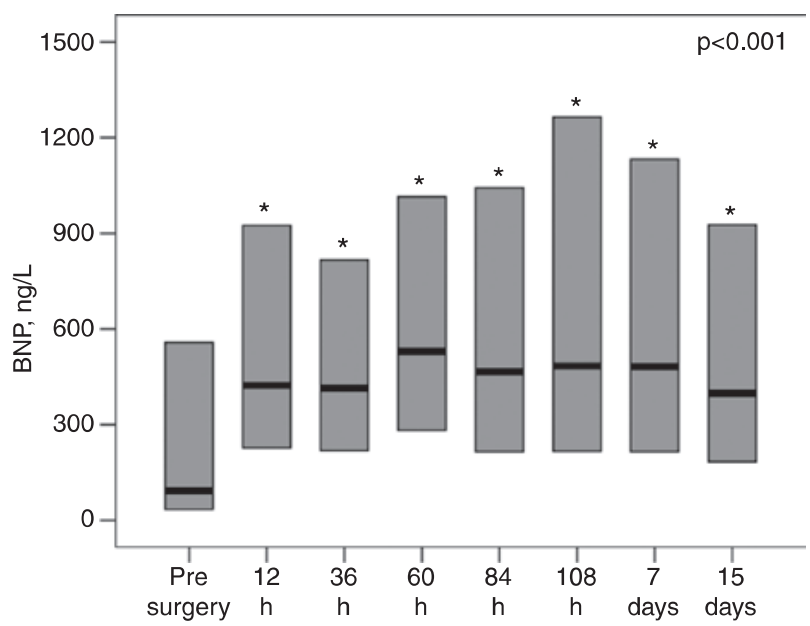

Figure 1: $B N P(n g / L)$ post-surgical response in the overall population. Bold horizontal line $=$ median; box $=$ interquartile range. ${ }^{*} p<0.001$ for differences with pre-surgery levels.

Table 2: Spearman's $\rho$ correlation coefficients between BNP and patients characteristics.

\begin{tabular}{lrr}
\hline & BNP pre & BNP peak post-surgery \\
\hline Aristotele score & $0.34^{\mathrm{a}}$ & $0.36^{\mathrm{a}}$ \\
BSA Haycock & $-0.66^{\mathrm{a}}$ & $-0.67^{\mathrm{a}}$ \\
TTE, h & $0.53^{\mathrm{a}}$ & $0.60^{\mathrm{a}}$ \\
Hours in ICU & $0.52^{\mathrm{a}}$ & $0.60^{\mathrm{a}}$ \\
Inotropic time, h & $0.42^{\mathrm{a}}$ & $0.61^{\mathrm{a}}$ \\
\hline
\end{tabular}

${ }^{a} p<0.001$. Table reports only significant correlations. BSA, body surface area; h, hours; ICU, intensive care unit; TTE, time to extubation.

\section{BNP in different CHD}

Significant differences $(\mathrm{p}<0.001)$ were found among all different CHD groups in BNP values pre- and post-operatively, with higher BNP values in complex CHD (i.e., transposition of the great arteries, univentricular heart) (Figure 2A and B).

\section{Prediction model with traditional risk factors}

The prediction model including the traditional risk factors including age, Aristotle score and BSA was fitted using Cox proportional hazards model. Relevant violations were observed in the proportional hazards assumptions ( $\mathrm{p}=0.005$ ); so for the following analysis flexible parametric survival models were used, because this starting model must be nested in the finals models. The hazard ratios and observed statistical significance levels for all predictors of this model are displayed in Table 3.
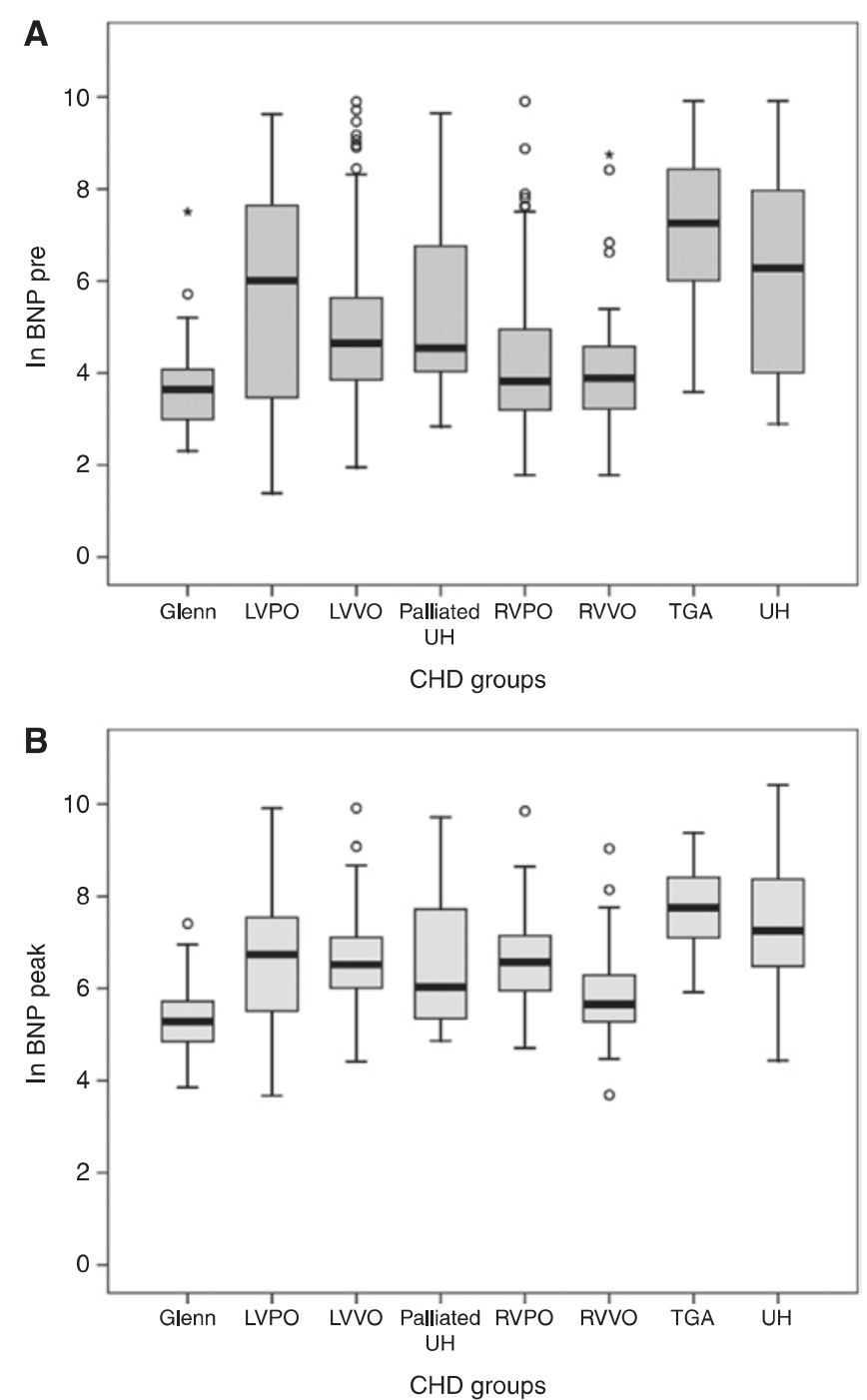

Figure 2: BNP values pre-surgery $(A)$ and peak $B N P$ values postsurgery $(B)$ in different CHD groups.

CHD groups Glenn: univentricular heart after partical pulmonary cavo-connection; LVVO, left ventricle volume overload (patenent arterial duct, ventricular septal defects, etc); LVPO, left ventricle pressure overload (aortic stenosis, aortic coarctation, etc); RVPO, right ventricle pressure overload (tetralogy of Fallot, pulmonary stenosis); RVVO, right ventricle volume overload (atrial septal defect, anmalous pulmonary venous drainage, etc); TGA, transposition of the great arteries, UH, univentricular heart; Palliated UH, univentricular heart after first stage of Norwood palliation.

Table 3: Flexible parametric survival model coefficients for standard risk factors (first model).

\begin{tabular}{lrrrr}
\hline & $\begin{array}{r}\text { Hazard } \\
\text { ratio }\end{array}$ & p-Value & $\begin{array}{r}95 \% \text { Confidence } \\
\text { interval }\end{array}$ \\
\hline Age, months & 1.025 & 0.000 & 1.012 & 1.039 \\
Aristotele score & 1.150 & 0.002 & 1.054 & 1.256 \\
BSA Haycock, m ${ }^{2}$ & 0.001 & 0.000 & 0.000 & 0.018 \\
\hline
\end{tabular}

BSA, body surface area. 
Table 4: Assessing the incremental predictive value of new biomarkers, comparing the first and the finals models.

\begin{tabular}{lrrrrr}
\hline & HR add marker & Ir test & C-statistic & NRI & Harrell's C \\
\hline First model+BNP & $1.404(1.103-1.786)$ & 0.006 & $0.720(p<0.001)$ & $0.089(p=0.048)$ & 0.834 \\
First model+CPB & $1.001(0.998-1.004)$ & 0.582 & $0.679(p=0.962)$ & $0.009(p=0.556)$ & $\ldots . .-$ \\
First model+12 h LACTAT & $1.165(1.057-1.284)$ & 0.008 & $0.656(p=0.099)$ & $0.031(p=0.533)$ & 0.831 \\
First model+12 h LACTAT+BNP & $1.445(1.100-1.899)$ & 0.009 & $0.698(p<0.001)$ & $0.139(p=0.003)$ & 0.840 \\
\hline
\end{tabular}

BNP, brain natriuretic peptide (log transformed); CPB, cardiopulmonary bypass time; HR, hazard ratio; NRI, net reclassification index.

\section{Effect of adding CPB time and end-operative arterial lactate levels to the traditional risk model}

CPB time showed no significant incremental predictive value compared to the model including the traditional risk factors in calibration, discrimination and reclassification tests. Consequently, CPB was not included in the final model. Conversely, end-operative serum lactate produced on the model fit was observed, although no significant effects in reclassification and discrimination tests were observed (Table 4). Therefore, the end-operative arterial serum lactate was included in the second risk model as a predictive variable.

\section{Evaluation of the incremental effect of BNP}

Pre-operative BNP levels showed no statistical incremental effects in calibration, discrimination and reclassification tests. On the contrary BNP peak values (log-transformed) showed significant incremental effects. Two other models were carried out: in the first, BNP peak values were added as continuous predictors to the previous model with traditional risk factors; in the second, both end-operative arterial lactate and BNP peak values were added as continuous predictors.

In both models hazard ratios for BNP peak values were highly significant (respectively $\mathrm{HR}=1.40, \mathrm{p}=0.006$; $\mathrm{HR}=1.44, \mathrm{p}=0.008$ ), and the log-likelihood improved with the addition of BNP to the prediction model with traditional risk factors $(p=0.006, p=0.009$, respectively). The ROC curves for the model with traditional risk factors, without and with BNP peak values, are presented in Figure 3. BNP peak values significantly $(\mathrm{p}<0.001)$ modified the ROC analysis (Table 4). Reclassification data for subjects with and without events are summarized in Table 5. In particular, significant $(\mathrm{p}<0.001)$ net gain in reclassification proportion of 0.074 was observed in the model including the BNP peak values for subjects, who did not experience an event (with 46 individuals reclassified down and 9 reclassified up). The NRI including BNP peak values were estimated to be $0.089(\mathrm{p}<0.001)$. Based on the NRI and its components, we interpret that the addition of BNP peak values to the prediction model including only the traditional risk factors actually improved

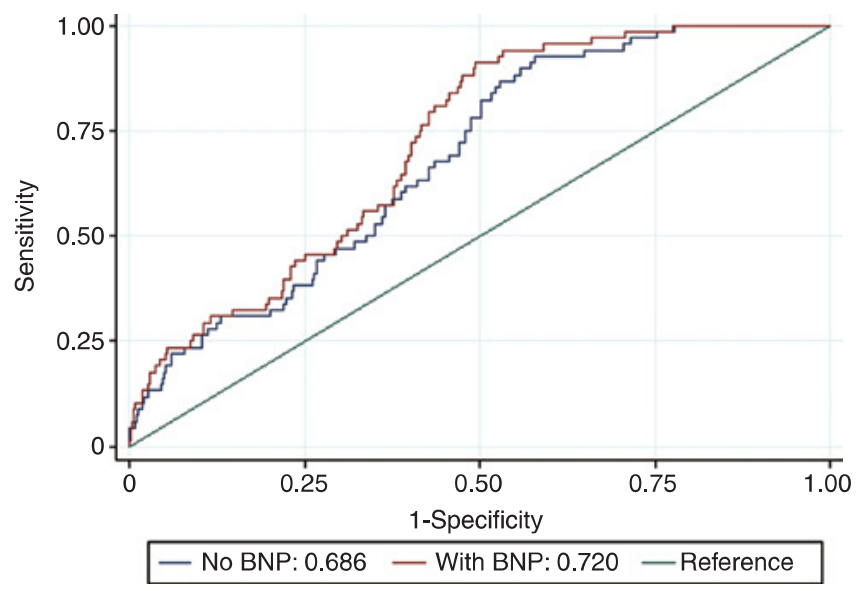

Figure 3: $R O C(\mathrm{ng} / \mathrm{L})$ analysis for the first risk prediction model with the adjunction of peak-BNP-log.

The area under the ROC curve (AUC) is indicated in the box at the bottom of the Figure.

Table 5: Reclassification among patients who experience an event and those who do not experience an event on follow-up.

\begin{tabular}{|c|c|c|c|c|}
\hline \multirow{2}{*}{$\begin{array}{l}\text { First model } \\
\text { without BNP } \\
\text { Frequency, Row\% }\end{array}$} & \multicolumn{3}{|c|}{ Model with BNP } & \multirow[t]{2}{*}{ Total } \\
\hline & $1^{\circ}$ tertile & $2^{\circ}$ tertile & $3^{\circ}$ tertile & \\
\hline \multicolumn{5}{|l|}{ Patients with event } \\
\hline $1^{\circ}$ tertile & $3(60.0)$ & $2(40.0)$ & $0(0.0)$ & 5 \\
\hline $2^{\circ}$ tertile & $1(3.2)$ & $28(90.3)$ & $2(6.5)$ & 31 \\
\hline $3^{\circ}$ tertile & $0(0.0)$ & $2(6.2)$ & $30(93.8)$ & 32 \\
\hline Total & 4 & 32 & 32 & 68 \\
\hline \multicolumn{5}{|c|}{ Patients without event } \\
\hline $1^{\circ}$ tertile & $182(97.3)$ & $5(2.7)$ & $0(0.0)$ & 187 \\
\hline $2^{\circ}$ tertile & $32(20.3)$ & $122(77.2)$ & $4(2.5)$ & 158 \\
\hline $3^{\circ}$ tertile & $0(0.0)$ & $14(9.0)$ & $142(91.0)$ & 156 \\
\hline Total & 214 & 141 & 146 & 501 \\
\hline
\end{tabular}

BNP, brain natriuretic peptide. 
classification for a net of $7 \%$ of individuals with nonevents, with no net loss for events. The NRI including BNP peak values to the second model was estimated to be $0.139(\mathrm{p}=0.003)$ (Table 4).

The Supplemental Figure 1 (that accompanies the article at http://www.degruyter.com/view/j/cclm.2015.53. issue-11/cclm-2014-1084/cclm-2014-1084.xml?format=INT) shows the internal validation of the model. Results of the calibration plot demonstrated a good concordance between predicted and observed events. Furthermore the model with BNP also showed a good discrimination (Harrell's c $=0.834$ ) (Table 4).

\section{Discussion}

Several studies have demonstrated independent associations of both pre- and post-operative BNP values with indices of outcome in children undergoing surgery for CHD [1-17]. However, adequate evaluation of a novel risk marker requires a sound research design, a representative at-risk population, and an adequate number of outcome events, as recommended by international guidelines [20]. Studies of a novel marker should report the degree to which it adds to the prognostic information provided by standard risk markers. In general, a novel risk biomarker should be evaluated in several phases, including specific statistical tests to assess marker ability in discrimination, calibration and reclassification of data sets [20]. The experimental protocol of the present study was designed to test the prognostic value of BNP in pediatric cardiac surgery in accordance with these criteria, as recommended by international guidelines [19-21]. In particular, our data indicates that the addition of BNP to a multivariate model, including conventional predictive variables (i.e., age, BSA, Aristotle score, CPB time) [24, 25], significantly improves the risk stratification in children undergoing CHD surgery.

In the present study, two risk prediction models were tested. The first model included few conventional risk factors (i.e., age, BSA, and Aristotle score) [23, 24], while the second one considered two additional parameters (CPB time and end-operative arterial lactate values). These operative parameters have recently been regarded as the best predictors of outcome in children undergoing cardiac surgery $[28,29]$. BNP, expressed as the peak value after surgery, showed an incremental improvement in the information of all risk prediction models (Table 4). It is noteworthy that the incremental contribution of BNP in explaining the variability of multivariate regression models was found to be higher than those of CPB time and end-operative arterial lactate values (i.e., the two most important clinical parameters). From a clinical point of view, it is important to consider that peak of BNP values occurs at different times at various ages, being on average at $60 \mathrm{~h}$ post-surgery. Thus, repeated measurement of BNP values in the post-operative period are advised in order to get the real peak.

Risk management includes the identification, assessment, and prioritization of risk [34, 35]. Stratification of risk helps to select those individuals needing more intensive interventions [34-37]. Accurate risk assessment should drive allocation of clinical resources, promote preventive therapies and/or more intensive post-surgery management, aiming to ameliorate patient outcome and finally reduce costs [34-37]. It is therefore plausible that the routine use of BNP assay, by improving risk prediction, may help the clinician to better manage pediatric patients undergoing cardiac surgery, potentially improving outcome [38]. However, randomized clinical trials are needed to definitively demonstrate the cost effectiveness of BNP assay in the management of children with CHD.

\section{Strengths and limitations}

This study has several strengths. We used a prospective cohort design and a rigorous protocol to collect specimens. This study represents the largest cohort of children undergoing cardiac surgery for CHD reported so far with inclusion of all major groups of CHD. The study does have some limitations. First, the total number of subjects is relatively low compared to large trials performed in adults. Studies with a larger number of children are recommended in order to differentiate among the specific forms of CHD and age groups. Furthermore further studies on redo-surgery patients that have been excluded from our initial protocol may be also helpful.

Second, blood samples for research purposes were reduced for ethical reasons. Consequently, the number of blood determinations were limited, although much higher than those of previously published studies. The difficulty in performing blood samples in children, especially neonates need to be considered. The evaluation of peak values implies the need for multiple BNP measurements at various times. Finally, from a statistical point of view, even though the NRI results are convincing, caution needs to be exercised in their interpretation because of being dependent on the rather arbitrary choice of categories. 


\section{Conclusions}

Our study demonstrated for the first time that BNP, expressed as peak after surgery, shows an independent and incremental prognostic value in multivariable models including conventional risk factors such as age, BSA, Aristotle score, CPB time and end-operative arterial lactate values. Our study may be considered as groundwork for the design of pediatric-specific randomized clinical trial, which is needed to definitively demonstrate the cost effectiveness of BNP assay in the management of children with CHD.

Author contributions: All the authors have accepted responsibility for the entire content of this submitted manuscript and approved submission.

Financial support: None declared.

Employment or leadership: None declared.

Honorarium: None declared.

Competing interests: The funding organization(s) played no role in the study design; in the collection, analysis, and interpretation of data; in the writing of the report; or in the decision to submit the report for publication.

\section{References}

1. Yancy CW, Jessup M, Bozkurt B, Butler J, Casey DE Jr, Drazner MH, et al. 2013 ACCF/AHA guideline for the management of heart failure: a report of the American College of Cardiology Foundation/ American Heart Association Task Force on practice guidelines. Circulation 2013;128:e240-327.

2. Nir A, Lindinger A, Rauh M, Bar-Oz B, Laer S, Schwachtgen L, et al. NT-pro-B-type natriuretic peptide in infants and children: reference values based on combined data from four studies. Pediatr Cardiol 2009;30:3-8.

3. Cantinotti M, Giovannini S, Murzi B, Clerico A. Diagnostic, prognostic and therapeutic relevance of B-type natriuretic peptide assay in children with congenital heart diseases. Clin Chem Lab Med 2011;49:567-80.

4. Cantinotti M, Storti S, Parri MS, Murzi M, Clerico A. Reference values for plasma BNP circulating levels in the first days of life. Clin Chem 2009;55:1438-40.

5. Berry JG, Askovich B, Shaddy RE, Hawkins JA, Cowley CG. Prognostic value of $B$-type natriuretic peptide in surgical palliation of children with single-ventricle congenital heart disease. Pediatr Cardiol 2008;29:70-5.

6. Cantinotti M, Storti S, Ripoli A, Zyw L, Crocetti M, Assanta N, et al. Diagnostic accuracy of BNP assay for congenital heart disease in the first month of life. Clin Chem Lab Med 2010;48:1333-8.

7. Hsu JH, Keller RL, Chikovani O, Cheng H, Hollander SA, Karl TR, et al. B-type natriuretic peptide levels predict outcome after neonatal cardiac surgery. J Thorac Cardiovasc Surg 2007;134:939-45.

8. Walsh R, Boyer C, LaCorte J, Azakie A, Karl TR, Harmon C, et al. $\mathrm{N}$-terminal B-type natriuretic peptide levels in pediatric patients with congestive heart failure undergoing cardiac surgery. J Thorac Cardiovasc Surg 2008;135:98-105.
9. Shih CY, Sapru A, Oishi P, Azakie A, Karl TR, Harmon C, et al. Alterations in plasma B-type natriuretic peptide levels after repair of congenital heart defects: a potential perioperative marker. J Thorac Cardiovasc Surg 2006;131:632-8.

10. Cannesson M, Bionda C, Gostoli B, Raisky O, di Filippo S, Bompard D, et al. Time course and prognostic value of plasma B-type natriuretic peptide concentration in neonates undergoing the arterial switch operation. Anesth Analg 2007;104: 1059-65, tables of contents.

11. Mir TS, Haun C, Lilje C, Läer S, Weil J. Utility of N-terminal brain natriuretic peptide plasma concentrations in comparison to lactate and troponin in children with congenital heart disease following open-heart surgery. Pediatr Cardiol 2006;27:209-16.

12. Kitzsteiner T, Zink S, Cesnjevar R, Singer H. Impact of cardiac surgery on plasma levels of B-type natriuretic peptide in children with congenital heart disease. Int J Cardiol 2007;114:339-44.

13. Gessler P, Knirsch W, Schmitt B, Rousson V, von Eckardstein A. Prognostic value of plasma $\mathrm{N}$-terminal pro-brain natriuretic peptide in children with congenital heart defects and open-heart surgery. J Pediatr 2006;148:372-6.

14. Niedner MF, Foley JL, Riffenburgh RH, Bichell DP, Peterson BM, Rodarte A. B-type natriuretic peptide: perioperative patterns in congenital heart disease. Congenit Heart Dis 2010;5:243-55.

15. Cantinotti M, Storti S, Lorenzoni V, Arcieri L, Moschetti R, Murzi B, et al. The combined use of neutrophil gelatinaseassociated lipocalin and brain natriuretic peptide improves risk stratification in pediatric cardiac surgery. Clin Chem Lab Med 2012;50:2009-17.

16. Cantinotti M, Storti S, Lorenzoni V, Murzi B, Marotta M, Crocetti $M$, et al. Response of cardiac endocrine function to surgery stress is age dependent in neonates and children with congenital heart defects: consequences in diagnostic and prognostic accuracy of brain natriuretic peptide measurement. Pediatr Crit Care Med 2013;14:508-17.

17. Cantinotti M, Law Y, Vittorini S, Crocetti M, Marco M, Murzi B, et al. The potential and limitations of plasma BNP measurement in the diagnosis, prognosis, and management of children with heart failure due to congenital cardiac disease: an update. Heart Fail Rev 2014;19:727-42.

18. Pletcher MJ, Pignone M. Evaluating the clinical utility of a biomarker: a review of methods for estimating health impact. Circulation 2011;123:1116-24.

19. Wang TJ. Assessing the role of circulating, genetic, and imaging biomarkers in cardiovascular risk prediction. Circulation 2011;123:551-65.

20. Hlatky MA, Greenland P, Arnett DK, Ballantyne CM, Criqui MH, Elkind MS, et al. Criteria for evaluation of novel markers of cardiovascular risk: a scientific statement from the American Heart Association. Circulation 2009;119:2408-16.

21. Prontera C, Storti S, Emdin M, Passino C, Zyw L, Zucchelli GC, et al. Comparison of a fully automated immunoassay with a point-of-care testing method for B-type natriuretic peptide. Clin Chem 2005;51:1274-6.

22. Lopez L, Colan SD, Frommelt PC, Ensing GJ, Kendall K, Younoszai AK, et al. Recommendations for quantification methods during the performance of a pediatric echocardiogram: a report from the Pediatric Measurements Writing Group of the American Society of Echocardiography Pediatric and Congenital Heart Disease Council. J Am Soc Echocardiogr 2010;23:465-95. 
23. Jacobs JP, Jacobs ML, Austin EH, Mavroudis C, Pasquali SK, Lacour-Gayet FG, et al. Quality measures for congenital and pediatric cardiac surgery. World J Pediatr Congenit Heart Surg 2012;3:32-47.

24. Jonas RA, Jacobs JP, Jacobs ML, Mavroudis C. Reporting of mortality associated with pediatric and congenital cardiac surgery. J Thorac Cardiovasc Surg 2010;140:726; author reply 726-7.

25. Lacour-Gayet F, Clarke D, Jacobs J, Comas J, Daebritz S, Daenen W, et al. The Aristotle score: a complexity-adjusted method to evaluate surgical results. Eur J Cardiothorac Surg 2004;25:911-24.

26. Portman MA, Slee A, Olson AK, Cohen G, Karl T, Tong E, et al. Triiodothyronine supplementation in infants and children undergoing cardiopulmonary bypass (TRICC): a multicenter placebo-controlled randomized trial: age analysis. Circulation 2010;14:S224-33.

27. Cnaan A, Laird NM, Slasor P. Using the general linear mixed model to analyze unbalanced repeated measure and longitudinal data. Stat Med 1997;16:2349-80.

28. Alves RL, Aragão e Silva AL, Kraychete NC, Campos GO, Martins Mde J, Módolo NS. Intraoperative lactate levels and postoperative complications of pediatric cardiac surgery. Paediatr Anaesth 2012;22:812-7.

29. Park SJ, Kim HS, Byon HJ, Kim CS, Cheong IY, Kim JT. Intraoperative plasma lactate as an early indicator of major postoperative events in pediatric cardiac patients. Tohoku J Exp Med 2012;228:239-45.

30. Royston P, Parmar R. Flexible parametric proportional-hazards and proportional-odds models for censored survival data, with application to prognostic modelling and estimation of treatment effects. Stat Med 2002;21:2175-97.
31. DeLong ER, DeLong DM, Clarke-Pearson DL. Comparing the areas under two or more correlated receiver operating characteristic curves: a nonparametric approach. Biometrics 1988;14:837-45.

32. Pencina MJ, D’Agostino RB Sr, D’Agostino RB Jr, Vasan RS. Evaluating the added predictive ability of a new marker: from area under the ROC curve to reclassification and beyond. Stat Med 2008;27:157-72; discussion 207-12.

33. Harrell FE Jr, Lee KL, Mark DB. Multivariable prognostic models: issues in developing models, evaluating assumptions and adequacy, and measuring and reducing errors. Stat Med 1996;15:361-87.

34. Hubbard D. The failure of risk management: why it's broken and how to fix it. Hokboken, NJ: John Wiley \& Sons, 2009:46.

35. Wood G, Barayan G, Sanchez DC, Inoue GN, Buchalla CA, Rossini GA, et al. Validation of the pediatric surgical risk assessment scoring system. J Pediatr Surg 2013;48:2017-21.

36. Available from: http://www.qpidhealth.com. Accessed: 6 Oct 2014.

37. Lloyd-Jones DM. Cardiovascular risk prediction: basic concepts, current status, and future directions. Circulation 2010;121:1768-77.

38. Vanderlaan RD, Manlhiot C, Conway J, Honjo O, McCrindle BW, Dipchand A. Perioperative factors associated with in-hospital mortality or retransplantation in pediatric heart transplant recipients. J Thorac Cardiovasc Surg 2014;148:282-9.

Supplemental Material: The online version of this article (DOI: 10.1515/cclm-2014-1084) offers supplementary material, available to authorized users. 
Copyright of Clinical Chemistry \& Laboratory Medicine is the property of De Gruyter and its content may not be copied or emailed to multiple sites or posted to a listserv without the copyright holder's express written permission. However, users may print, download, or email articles for individual use. 